\title{
Role of streptokinase in the treatment of acute loculated parapneumonic pleural effusions and empyema
}

Demosthenes Bouros, Sophia Schiza, Panagiotis Panagou, John Drositis, Nikolaos Siafakas

\begin{abstract}
Background - Intrapleural administration of streptokinase has been shown in a few small series to be effective treatment for complicated parapneumonic effusions and pleural empyemas, but techniques of instillation of streptokinase differ. The role of streptokinase in promoting drainage was investigated prospectively in a larger series of patients with complicated parapneumonic effusions and pleural empyemas.
\end{abstract}

Methods - Twenty consecutive patients with parapneumonic effusions, 15 with complicated parapneumonic effusions and five with pleural empyemas, drawn from 160 patients presenting with pleural effusions were studied. The age of the patients ranged from 15 to 92 years. Initial thoracocentesis showed mean (SD) values of pH $7 \cdot 1(0 \cdot 15)$, glucose $45.9(17.5) \mathrm{mg} / \mathrm{dl}$, white blood cell count $12000(6627) / \mathrm{mm}^{3}$. Streptokinase was administered intrapleurally in a single daily dose of $\mathbf{2 5 0 0 0 0}$ units in $100 \mathrm{ml}$ normal saline via the chest tube once the drainage was $<100 \mathrm{ml} / 24$ hours. Patients were treated for 3-10 (mean 6) days.

Results - Following administration of streptokinase a clinical and radiological improvement was noted in all but one patient who died on the fourth day of hospitalisation due to widespread adenocarcinoma. Another patient with clinical but minimal radiological improvement underwent thoracotomy, but a clear pleural space with only fibrotic changes was found. The mean (SD) volume of fluid drained 24 hours before streptokinase was 42.5 (39) $\mathrm{ml}$, which increased in the first 24 hours after streptokinase to 334 (130) ml. Radiological evaluation showed an excellent improvement in 14 of the 20 patients, a moderate improvement in three, and minimal improvement in the remaining three patients. One patient developed a high fever as an adverse reaction to streptokinase. All 19 patients who completed the treatment were well at follow up 6-30 months (mean 15 months) later.

Conclusions - Intrapleural instillation of streptokinase is an effective and safe mode of treatment for complicated parapneumonic effusions and pleural empyemas and alleviates the need for thoracotomy.

(Thorax 1994;49:852-855)

The spectrum of pleural involvement associated with bacterial pneumonias includes simple parapneumonic effusions, complicated parapneumonic effusions, and pleural empyema. ${ }^{1-3}$ Potential complications range from chronic empyema to disseminated abscesses and death. ${ }^{45}$ The best methods for treating complicated parapneumonic effusions and pleural empyemas remain debatable. Only a few prospective randomised trials have been performed to guide intervention. In addition to antibiotic therapy, it is obligatory to secure adequate drainage to prevent the development of complications. ${ }^{67}$

Drainage interventions in multiloculated parapneumonic effusions or pleural empyemas include: (1) bedside chest tube placement into the largest loculus, (2) multiple computed tomographic or ultrasound-guided attempts at drainage, (3) open thoracotomy with chest tube placement, (4) pleural decortication, and (5) chest tube placement with instillation of intrapleural streptokinase or urokinase. ${ }^{4}$

The initial use of fibrinolytic enzymes for the treatment of haemothorax and post-pneumonic empyema was described in the 1950 s. $^{89}$ These results were encouraging, but allergic reactions and other side effects resulted in its abandonment. The subsequent availability of purified streptokinase has caused a resurgence of its use in intrapleural fibrinolysis. ${ }^{10-17}$ However, reports detail only a few patients and no firm criteria for its use or controlled studies are available. Furthermore, the optimum dose, duration, and safety of the method has not been studied extensively. The rationale for the use of streptokinase is its ability to lyse loculae, resulting in increased fluid drainage.

At a recent symposium only $14 \%$ of the respondents preferred the use of chest tube placement with intrapleural streptokinase for 
Patient characteristics and pleural fluid data of 20 patients with complicated parapneumonic effusion or empyema

\begin{tabular}{|c|c|c|c|c|c|c|c|}
\hline \multirow{2}{*}{$\begin{array}{l}\text { Patient } \\
\text { No. }\end{array}$} & \multirow{2}{*}{$\begin{array}{l}\text { Age } \\
\text { (years) }\end{array}$} & \multirow{2}{*}{$\begin{array}{l}\text { Underlying illness or } \\
\text { predisposing factor }\end{array}$} & \multirow[t]{2}{*}{ Sputum culture } & \multirow[t]{2}{*}{ Pleural fluid culture } & \multicolumn{3}{|c|}{ Pleural fluid culture } \\
\hline & & & & & $p H$ & $\begin{array}{l}\text { Glucose } \\
\text { (mg/dl) }\end{array}$ & $\begin{array}{l}\text { WBC } \\
\left(\text { per } \mathrm{mm}^{3}\right)\end{array}$ \\
\hline 1 & 26 & IV drug abuse & - & - & $7 \cdot 1$ & 35 & 6600 \\
\hline 2 & 85 & - & - & - & $7 \cdot 02$ & 28 & 4800 \\
\hline 3 & 72 & - & - & Staph aureus & $7 \cdot 01$ & 40 & 13100 \\
\hline 4 & 65 & - & - & - & $6 \cdot 8$ & 50 & 9800 \\
\hline 5 & 92 & Lung adenocarcinoma & Ps aeruginosa & - & $7 \cdot 2$ & 72 & 7900 \\
\hline 6 & 49 & - & - & Str uritis & $7 \cdot 3$ & 30 & 3200 \\
\hline 7 & 58 & Alcohol abuse & - & - & $7 \cdot 01$ & 35 & 11200 \\
\hline 8 & 37 & - & - & - & $7 \cdot 2$ & 65 & 4500 \\
\hline 9 & 55 & Periodontal disease & - & - & $7 \cdot 3$ & 57 & 2800 \\
\hline 10 & 60 & Periodontal disease & Staph hominis & - & $7 \cdot 3$ & 67 & 16000 \\
\hline 11 & 77 & - & - & - & $6 \cdot 9$ & 20 & 17000 \\
\hline 12 & 15 & - & - & - & $7 \cdot 3$ & 65 & 13000 \\
\hline 13 & 19 & - & - & - & $7 \cdot 1$ & 65 & 18000 \\
\hline 14 & 22 & Epilepsy, aspiration & - & $\begin{array}{l}\text { Peptostreptococcus magnus } \\
\text { Ps aeruginosa }\end{array}$ & $7 \cdot 0$ & 40 & 29000 \\
\hline 15 & 20 & - & - & 13 aeruginosa & $7 \cdot 2$ & 55 & 15500 \\
\hline 16 & 22 & Head injury, aspiration & - & - & 6.9 & 60 & 16000 \\
\hline 17 & 21 & - & - & - & $7 \cdot 1$ & 51 & 9800 \\
\hline 18 & 56 & Squamous cell lung carcinoma & Ps aeruginosa & Ps aeruginosa & $7 \cdot 0$ & 20 & 16500 \\
\hline 19 & 48 & Sub-diaphragmatic infection & - & Bacteroides ureolyticus & $7 \cdot 3$ & 15 & 12800 \\
\hline 20 & 28 & Head injury, aspiration & - & - & $7 \cdot 0$ & 48 & 2200 \\
\hline
\end{tabular}

the treatment of anaerobic multiloculated empyema. Most (49\%) preferred pleural decortication. ${ }^{6}$

This study investigates the efficacy and safety of streptokinase, used as an adjunct to chest tube drainage, in the management of 20 patients with complicated parapneumonic effusions and pleural empyemas.

\section{Methods}

PATIENTS

Between January 1990 and July 1993160 patients with benign pleural effusions were admitted to our hospital, 15 with complicated parapneumonic effusions and five parapneumonic pleural empyemas. Patients with pleural empyema had pus on thoracocentesis, positive pleural fluid cultures, and concomitant pneumonia, irrespective of the number of white blood cells in the pleural fluid. ${ }^{12}$ Patients with a complicated pleural effusion had a multiloculated effusion confirmed by chest computed tomographic scanning, ultrasound, or both, which did not resolve with a single tube thoracostomy. The median age of the patients was 48.5 (range 15-92) years; 14 were men. All were studied prospectively. Criteria for inclusion in the study were multiloculated pleural effusion confirmed by computed tomography, ultrasound, or both, and failure of drainage via a thoracostomy $(<100 \mathrm{ml}$ during the last 24 hours). Exclusion criteria were the presence of florid sepsis and a history of allergy to streptokinase.

Underlying diseases or predisposing factors for the development of pneumonic infection were alcohol abuse (one patient), lung malignancy with post-obstructive pneumonia (two), intravenous drug abuse (one), head injury with coma and aspiration (two), epilepsy with aspiration (one), subdiaphragmatic infection (one), and periodontal disease (two). In the remaining 10 patients no predisposing factors or underlying diseases were identified.

No patient had positive blood cultures for common pathogens. Sputum cultures were positive in three patients and pleural fluid cultures positive in five, three of whom also had positive sputum cultures (table). No patient had a history of allergy to streptokinase.

\section{STREPTOKINASE INSTILLATION}

Closed intercostal drainage was carried out using a chest tube with an indwelling trocar (Argyle, Sherwood Medical Company, Tullamore, Ireland) attached to an underwater seal system. Streptokinase was administered intrapleurally on a daily basis as a solution of 250000 units in $100 \mathrm{ml}$ normal saline via the chest tube. The tube was subsequently clamped for three hours before being reopened to suction. The time from chest tube placement to administration of streptokinase ranged from one to three days. The number of instillations ranged from three to 10 , mean 6 (2). Streptokinase was reinstilled if, on ultrasound examination, a persistent pleural effusion was seen, and the amount of pleural fluid drainage was below $100 \mathrm{ml}$ during the previous 24 hours.

\section{ASSESSMENT}

The effectiveness of the protocol was assessed by: (1) chest radiography, (2) serial chest ultrasound or computed tomographic scanning, or both, (3) monitoring the volume of fluid drained from the chest tube daily, and (4) clinically. Changes in pyrexia before and after starting streptokinase were also recorded.

The radiographic improvement was evaluated independently by two specialists, a respiratory physician and a radiologist. The last chest radiograph before starting treatment with streptokinase was compared with the chest radiograph taken at the end of the streptokinase administration. In order to score the changes in the chest radiographs the dimension of the pleural effusion was estimated by measuring the two maximal diameters at right angles to each other. An arbitrary scoring system was used: 0 (no change), 1 (less than one third improvement), 2 (improvement between one and two thirds), and 3 (more than two thirds improvement). In cases of interobserver disagreement the lower score was used. The volume of pleural fluid drained from the chest tube was recorded daily, as well as the total 


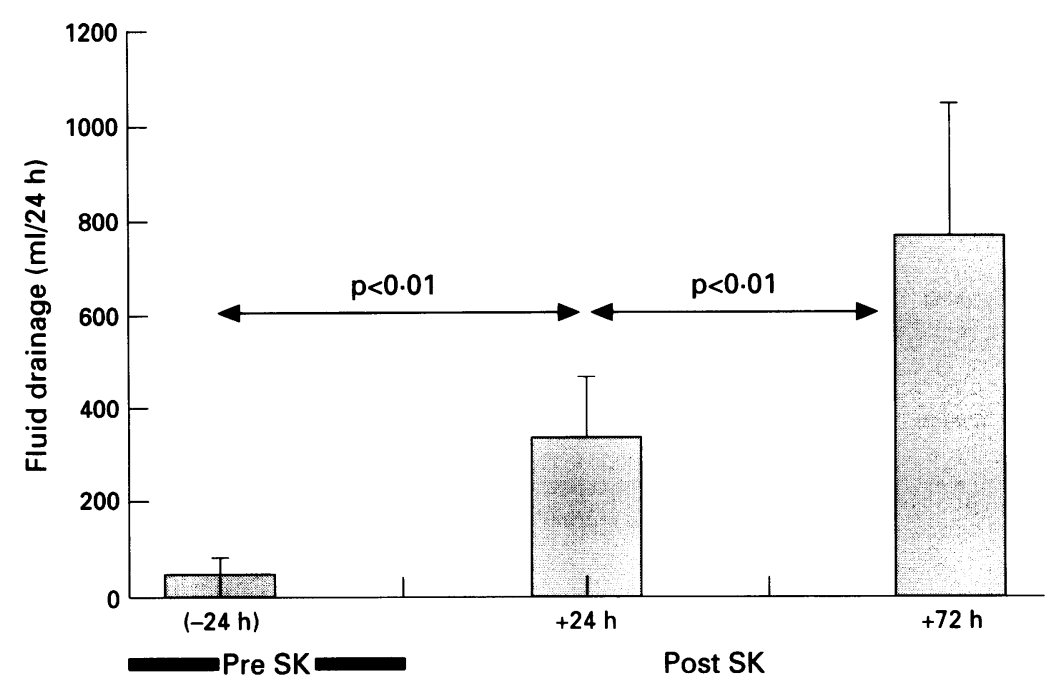

Mean (SD) volume of pleural fluid drained 24 hours before (pre $S K,-24 h$ ), and 24 and 72 hours after treatment with streptokinase (post $S K,+24 h$ and $+72 h$ ). $A$ significant increase is seen after streptokinase administration $(p<0 \cdot 01)$.

amount of solution instilled into the pleural cavity. Body temperature was recorded every three hours and the maximum measurements before and after streptokinase administration were compared. The duration of the pleural effusion before commencing streptokinase treatment ranged from 2-15 days. The protocol was approved by the ethics committee of the institution.

\section{PLEURAL FLUID DATA}

Pleural fluid analysis on initial thoracocentesis showed features of an exudate in all patients (table). Measurements included (a) $\mathrm{pH}$ determined by a blood gas machine AVL-995 (mean $7 \cdot 1(0 \cdot 15)$, range $6 \cdot 8-7 \cdot 3)$; (b) glucose (determined by the photometric method) was $\leqslant 70 \mathrm{mg} / \mathrm{dl}$ in all patients (mean $45.9(17.5)$ $\mathrm{mg} / \mathrm{dl}$, range $15-70 \mathrm{mg} / \mathrm{dl}$ ); (c) white blood cells (determined by the Coulter haematologic analyser) were elevated in all patients (mean $11485 / \mathrm{mm}^{3}$, range $2200-29000 / \mathrm{mm}^{3}$ ); (d) macroscopically turbid fluid was found in all but five patients, in whom it was frankly purulent.

\section{ANTIBIOTICS}

Fifteen patients $(75 \%)$ were taking antibiotics before admission to the study. During their hospital stay they received a combination of antibiotics covering both aerobic and anaerobic bacteria.

\section{FOLLOW UP}

All patients were followed up for a mean period of 15 months (range 6-30) with clinical examination, chest radiography, and/or ultrasound or computed tomographic scanning of the thorax.

\section{STATISTICAL ANALYSIS}

All values are expressed as mean (SD). Comparison of means between groups was performed with the $\chi^{2}$ test and the one way analysis of variance, $p$ values $\leqslant 0.05$ being considered significant.

\section{Results}

Clinical improvement in terms of fever, dyspnoea, discomfort, and debilitation, was noted after streptokinase in all but one patient (case no. 5). This patient died on the fourth day after streptokinase instillation of a diffuse metastatic lung adenocarcinoma, but at necropsy the pleural cavity was clear. One patient underwent surgical intervention 20 days after streptokinase because of inadequate radiological improvement and residual findings on ultrasound examination, but at thoracotomy the pleural space was clear with only pleural thickening present. Body temperature fell in 15 of the patients 24 hours after starting streptokinase treatment. In four patients there was a small increase which returned to normal by the end of treatment. One patient developed a high fever $\left(39-40^{\circ} \mathrm{C}\right)$ after the initiation of streptokinase and after each instillation which returned to normal when streptokinase was replaced by urokinase at a dose of 40000 units in $100 \mathrm{ml}$ normal saline. No other adverse reactions or side effects were noted. All patients were doing well at follow up and only six showed minimal residual pleural thickening.

The mean (SD) volume of pleural fluid drained during the 24 hours before instillation of streptokinase was 42.5 (39) $\mathrm{ml}$ (range 0-90 $\mathrm{ml}$ ), the mean volume drained during the first 24 hours after instillation was 334 (130) $\mathrm{ml}$ (range $300-1320 \mathrm{ml}$ ), and the mean net total fluid drained was 1597 (659) $\mathrm{ml}$ (range $590-2600 \mathrm{ml}$ ) (figure). A significant increase in drainage was seen at 24 and 72 hours after streptokinase administration compared with the volume before streptokinase $(p<0 \cdot 01)$.

The overall improvement in the chest radiographic score was $2.55(0.95)$ by both observers. A score of 3 (excellent improvement) was noted in 14 patients, a score of 2 (moderate) in three, and another three had a score of 1 (minimal improvement only).

\section{Discussion}

In our series of patients with parapneumonic loculated pleural effusions streptokinase was used in a dose of 250000 units in $100 \mathrm{ml}$ normal saline with the chest drain clamped for three hours, an'd not four hours as suggested by Bergh et al. ${ }^{10}$ The reduction to three hours was to reduce possible adverse reactions without interfering with the fibrinolytic activity of streptokinase. Our results show that three hours seems adequate for fibrinolysis, and adverse reactions were fewer than previously reported. ${ }^{101315}$ The technique used and the number of instillations of streptokinase vary in other series. In our study the mean (SD) number of days during which streptokinase was instilled was 6 (2) although it had been recommended to treat for 10-14 days. ${ }^{10} \mathrm{~A}$ shorter duration of treatment (three or fewer instillations) was adequate in 12 patients treated by Henke and 
Leatherman ${ }^{16}$ who diluted the dose in $30-60 \mathrm{ml}$ normal saline and reduced the duration of chest tube clamping to two hours, again to minimise adverse reactions. They had a greater than $50 \%$ improvement in the chest radiograph in nine of 12 patients with loculated non-purulent parapneumonic effusions. In our study of 15 patients with complicated parapneumonic effusions and five with pleural empyemas a greater than $33 \%$ improvement in the chest radiograph was noted in 17 patients, including the five with pleural empyemas where streptokinase has been shown to have a lower efficacy. In one series ${ }^{11}$ satisfactory resolution of pleural empyemas occurred in only 12 of 27 cases. Although comparative studies of dose and duration of tube clamping do not exist, our technique appears to be safe, and the three hour duration of intrapleural tube clamping successfully cleared the pleural cavity. The higher number of streptokinase instillations in our study than in others ${ }^{131516}$ could be explained by differences in the stage of the pleural effusion, the underlying illness, or other predisposing factors including the amount of pleural fluid, the causative organism, the number of loculations, and the inclusion of patients with pleural empyemas.

Urokinase can be used instead of streptokinase because of its low antigenicity, ${ }^{18}$ but it is expensive and, as the incidence of adverse effects to purified streptokinase is low, its use will remain occasional.
1 Light RW, Girard WM, Jenkinson SG, Goerge RB. Parapneumonic effusion. Am $\mathcal{F}$ Med 1980;69:507-11

2 Light RW. Pleural diseases. Philadelphia: Lea and Febiger, 1983.

3 Maheshwari A, Nelson D, Sharma OM. Acute empyema: down but not out. F Respir Dis 1992;13:47-56.

4 Bartlett JG, Finegold SM. Anaerobic infections of the lung and pleural space. Am Rev Respir Dis 1974;110:56-77.

5 Sahn SA. The pleura. Am Rev Respir Dis 1988;138:184-234.

5 Sahn SA. The pleura. Am Rev Respir Dis 1988;138: 184-234.
6 Strange C, Sahn S. The clinician's perspective on parapneumonic effusions and empyema. Chest 1993;103:259-
pneme 61 .

7 Light RW. Parapneumonic effusions and empyema. Clin Chest Med 1985;6:55-62.

8 Tillet WS, Sherry S. The effect in patients of streptococcal fibrinolysis (streptokinase) and streptococcal desoxyribonuclease on fibrinous purulent, and sanguinous pleura exudations. $\mathcal{f}$ Clin Invest 1949;28:173-90.

9 Tillet WS, Sherry S, Read CT. Use of streptokinasestreptodornase in treatment of post pneumonic empyema. Streptodornase in treatment of Turg 1951;21:275-97.

10 Bergh NP, Ekroth R, Larsson S, Nagy P. Intrapleural streptokinase in the treatment of hemothorax and empyema. Scand $\mathcal{F}$ Thorac Cardiovasc Surg 1977;11:265-8.

11 Fraedrich G, Hoffmann D, Effenhauser P, Jander R. Instillation of fibrinolytic enzymes in the treatment of pleural empyema. Thorac Cardiovasc Surg 1982;30:36-8.

12 Ogirala RG, Williams MH Jr. Streptokinase in a loculated pleural effusion. Effectiveness determined by site of instillation. Chest 1988;94:884-6.

13 Mitchell ME, Alberts WM, Chandler KW, Goldman AL. Intrapleural streptokinase in management of parapneumonic effusions. Report of series and review of litpneumonic effusions. Report of series and

14 Willsie-Ediger SK, Salzman G, Reisz G, Foreman MG. Use of intrapleural streptokinase in the treatment of thoracic of intrapleural streptokinase in the treatment

15 Aye RW, Froese DP, Hill LD. Use of purified streptokinase in empyema and hemothorax. Am $\mathcal{f}$ Surg 1991;161:560-2.

16 Henke CA, Leatherman JW. Intrapleurally administered streptokinase in the treatment of acute loculated non purulent parapneumonic effusions. Am Rev Respir Dis 1992;145:680-4.

17 Aflageme I, Munoz F, Pena N, Umbrias. Empyema of the thorax in adults. Etiology, biologic findings, and management. Chest 1993;103:839-43.

18 Moulton JS, Moore PT, Mencini RA. Treatment of loculated pleural effusion with transcatheter intracavitary urokinase. $A 7 R$ 1989;153:941-5. 